\title{
On a law of distribution of inshore fishes.
}

\author{
$\mathrm{By}$ \\ Alexander Meek. \\ (Dove Marine Laboratory, Cullercoats, England.) \\ With 4 Text-figures.
}

\section{The Law.}

The district of the Northumberland Sea Fisheries Committee is divided for administrative purposes into a northern and a southern region. The two regions are about equal in extent. They present, when considered from a statistical point of view, interesting contrasts as to the relative quantities of the various kinds of fish landed by the inshore fishermen. These fishermen fish within the territorial limits and only to a slight extent in the waters just outside that area. It was pointed out, particularly in the Report of the Dove Marine Laboratory, Cullercoats, for the year 1904, that the two regions differ with respect to the hard ground, that of the northern being much more extensive than that of the southern. Beyond this there cannot be said to be any important apparent difference between the two regions.

In the report just referred to, it was stated that every year about $1,000,000$ crabs are landed in the northern district, and only some 350000 in the southern, the lobsters landed being ca. 20000 and 16500 respectively. The lobster-crab relationship of these districts and the districts immediately north and south of Northumberland, as shown by statistics is indicated in the following table:
N. St. Abbs district, $1: 95$ Northumberland N
$1: 56$
Northumberland S.
$1: 21$
North Eastern
$1: 41$
S. Eastern
$1: 34$ 
The two last distriets, especially that of the North Eastern Sea Fisheries Committee, are much larger than the others and would well deserve a study in detail. But sufficient is indicated to show that the proportions of the two species present interesting differences at different successive parts of the coast. There are regions in short where the crabs are numerous, and regions where they are relatively less numerous, and the same could be said with respect to lobsters. Not only so, but from what follows it will probably be found that such regions of abundance occur in successive waves all along the coast.

In the Report for 1905 it was shown that the two Northumberland districts presented interesting contrasts likewise when viewed from the point of view of the results of the trawling experiments. Every year the inshore waters of Northumberland are populated by flat-fish, mainly plaice and dabs. These reach a maximum in numbers during the summer and a minimum during the winter. The proportional eatch of flat-fish during the years, - since 1892 - the experiments have been made at the various stations is shown in the accompanying table:

\begin{tabular}{|c|c|c|c|c|c|c|}
\hline & Turbot & Brill & Sole & Plaice & Dab & Flounder \\
\hline $\begin{array}{l}\text { Northern: } \\
\text { Goswick ..... }\end{array}$ & 2 & 2 & - & 82 & 4 & 9 \\
\hline $\begin{array}{c}\text { Skate Roads... } \\
\text { Southern: }\end{array}$ & 2 & 1 & - & 81 & 11 & 5 \\
\hline Alnmouth ... & 1 & - & 2 & 41 & 51 & 5 \\
\hline Druridge . . . & 1 & - & 2 & 43 & 51 & 3 \\
\hline Cambois ...... & 1 & - & 3 & 22 & 72 & 2 \\
\hline Blyth . . . . & 1 & - & 2 & 43 & 51 & 3 \\
\hline
\end{tabular}

The contrast is even more apparent when the results are presented graphically (fig. 1). In the figure the stations are indicated according to their distances from one another. The northern stations - one to the north and the other to the south of Holy Island - are characterised by the relatively large proportion of plaice, and by few dabs. The southern stations present more dabs and fewer plaice. These features are not merely exhibited as an average of results but are found every year, and at all seasons.

As Alnmouth and Druridge are close together and also Cambois and Blyth, the contrasts may be presented in fewer figures as follows: 


\begin{tabular}{r||c|c|c|c|c|c}
\hline & Turbot & Brill & Sole & Plaice & Dab & Flounder \\
\hline \hline Northern ..... & 2 & 2 & - & 82 & 7 & 7 \\
Southern (a) ... & 1 & - & 2 & 42 & 51 & 4 \\
(b) . . . & 1 & - & 3 & 33 & 61 & 2
\end{tabular}

In Northumberland therefore it can be said that the plaice gradually increase in number from about Blyth in the south to about Berwick in the north; and that in the same region the dabs gradually increase in numbers in the opposite direction, - from north to south. It is apparent also with reference to the fewer numbers that turbot, brill and flounders are distributed similarly to plaice, and soles to dabs.

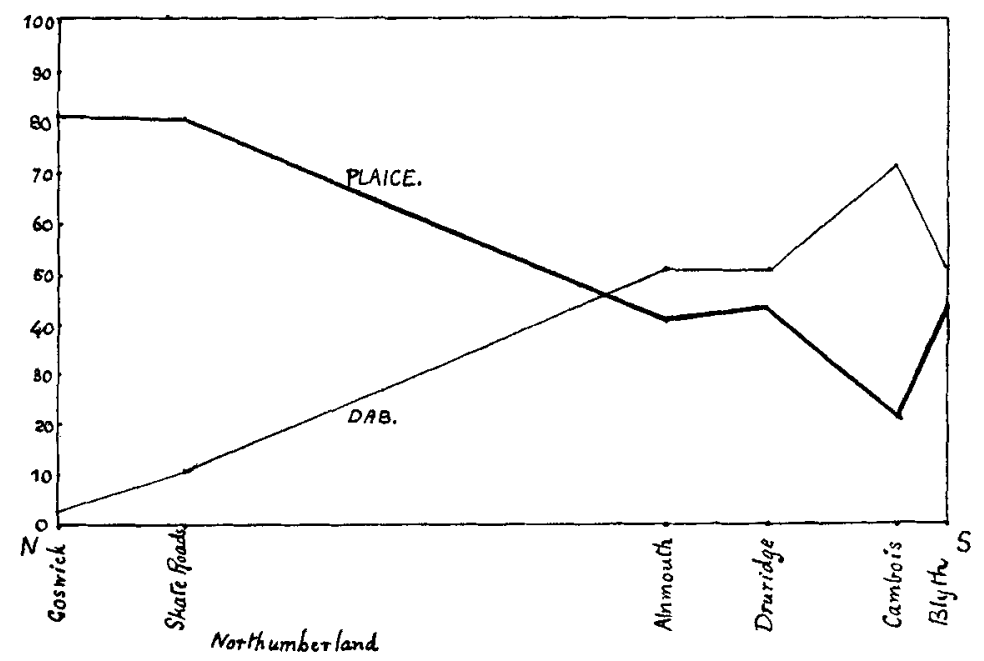

Fig. 1.

With this in mind the results of the trawling experiments made with the "Garland" on behalf of the Scottish Fishery Board have been brought under review. Even a glance at the results is sufficient to demonstrate that similarly certain of the stations stand out prominently with regard to the large proportion of plaice, and that these are similarly orientated to those of Northumberland. To present the case it was only found necessary to make an analysis of six successive years' results, and to rearrange the stations as in the 
following table, so that they appear in succession from north to south.

\begin{tabular}{|c|c|c|c|c|c|}
\hline \multicolumn{2}{|c|}{ Firth of Forth } & Plaice & Dab & Lemon Dab & Long Rough \\
\hline \multicolumn{2}{|c|}{ North: Station 6} & 55 & 22 & 17 & $\check{5}$ \\
\hline$"$ & $" 2$ & 35 & 43 & 10 & 11 \\
\hline$"$ & $" 4$ & $7 \check{0}$ & 18 & 4 & 2 \\
\hline South: & ” 7 & 17 & 58 & 4 & 19 \\
\hline
\end{tabular}

The mid-Forth stations have been neglected although it may here be said that they show about an average of the shore stations on either side.

In considering an estuarine region like that of the Forth with reference to inshore distribution it is necessary in the first place to grant that on the south side of the Firth a station up the Firth is to the north of a station further down. Station 4 is in this way north of station 7 . On the north side of the Firth likewise station 2 is further up the Firth than station 6 and is therefore further south. If the results as indicated above be considered in this way it will be found that they agree for each side of the Firth taken separately with those of Northumberland. viz. that the northern station presents more plaice and the southern station more dabs.

If however it be desired to leave out the up Forth stations altogether, station 6 on the north side may be contrasted with station 7 on the south, and the result again agrees with the distribution in Northumberland.

Seeing also that in St. Andrews Bay the proportion of plaice as caught by the "Garland" was found to be about 60 it also comes into relationship with the Forth stations as a northerly region rich in plaice.

'The recently published account of the trawling experiments of the "Goldseeker" by Prof. D'Arcy W. Thompson [1913 5 th Rep. (N. area) on Fishery and Hydrogr. Investigations] although it only gives the figures with reference to plaice, is welcome since it shows that the area of the Forth, St. Andrews' Bay and the coast just to the north of the Tay may be viewed as a whole and presents again a wave of distribution of plaice similar to that of Northumberland. The figures are rearranged to present this in the following table: 


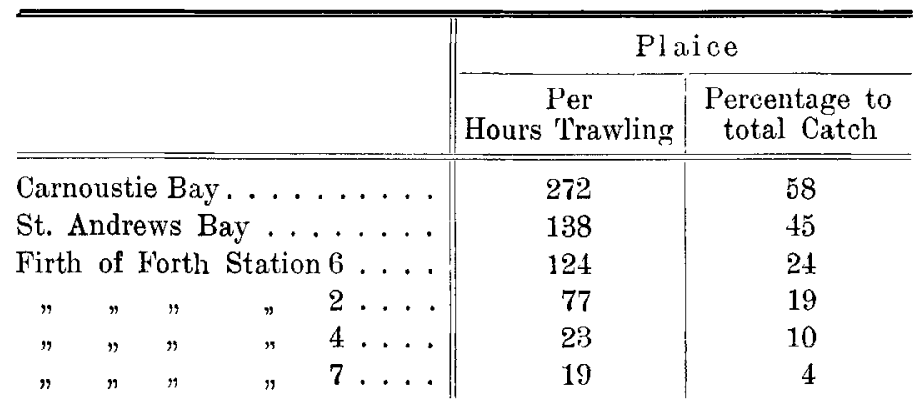

The results are even more convincing than those of the "Garland" due doubtless to the superiority of the vessel and of the gear. Like Northumberland the whole region from the south side of the Forth up to and including Carnoustie Bay and involving two estuaries is an area wherein the predominant flat-fish are distributed in a definite mannerIt will be interesting to see whether the results for dabs, when they are published, respond likewise to the law.

The "Garland" results show that further north in the neighbourhood of Montrose dabs are once more predominant. Off Aberdeen again the wave of plaice re-appears and there is another similar wave of plaice along the southern and inner portion of the Moray Firth.

To turn now to the region south of Northumberland, off the Durham coast, from an experiment made in 1897, it may be said that plaice are again predominant. The "Huxley" experiments in Bridlington Bay point to a second wave of plaice in the neighbourhood of Flamborough Head.

Plaice then are distributed along the coast not uniformly but definitely in successive localised regions of maxima and minima. The same is true of dabs, evidently of other flat-fish, and perhaps of round fish; apparently also it is the case with reference to such forms as crabs and lobsters. The interesting point to notice further at present is the one which has been

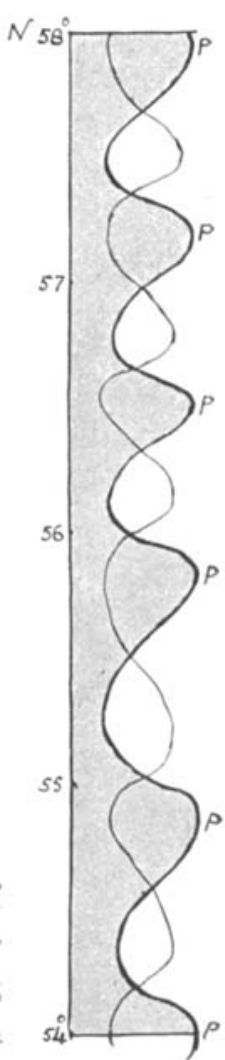

Fig. 2. proved by the above considerations, that in each region the plaice tend towards a maximum in the north and the dabs towards a 
maximum in the south. In other words the distribution when expressed graphically will present a sharp descent to the north for plaice and to the south for dabs. This may be. indicated in an idealised diagram which, however, is meant to picture the distribution from Flamborough to the Moray Firth (Fig. 2).

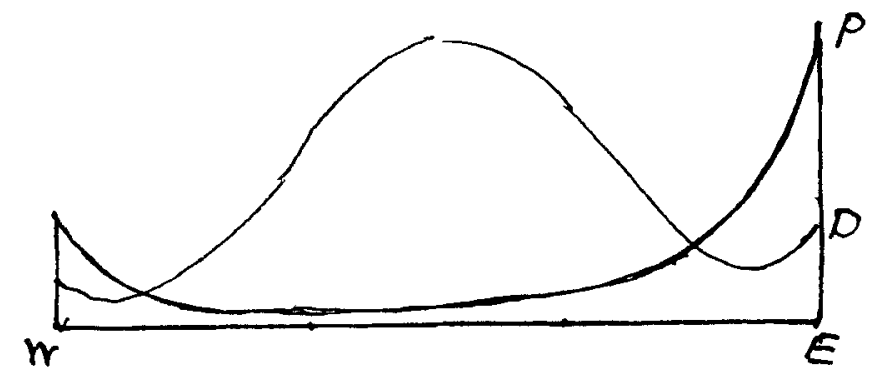

Fig. 3.

The first part of the law which I desire to present is that on the east coast of England and of Scotland the inshore plaice are distributed in regions which can be specified of maxima and minima. In a given area including a minimum region to the south and a maximum region to the north there is a gradual increase in the

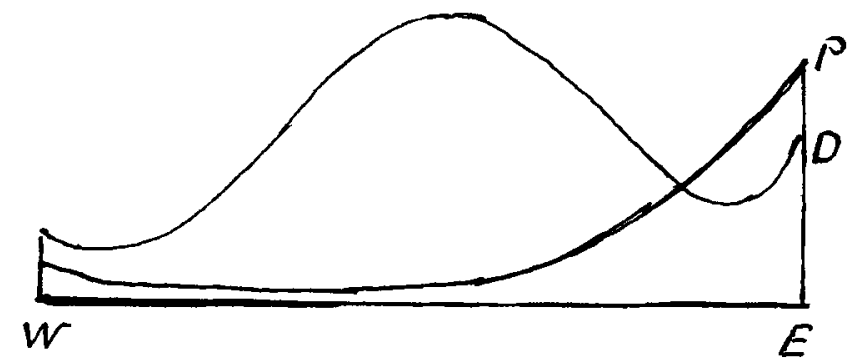

Fig. 4.

numbers of plaice from south to north. In the case of dabs the same areas present an opposite distribution, with an advancing increase to the south.

It is only in the regions of maxima that the plaice predominate, for immediately outside the territorial waters, or even before, the dabs predominate. A transverse section of the North Sea based on 
the plaice-dab relationship would give a picture like fig. 3 if taken through one of the plaice maxima, and as in fig. 4 if through one of the dab maxima regions. In the southern and eastern portions of the North Sea there is evidently one large plaice maximum region, but made up nevertheless of such maxima and minima.

But a fine analysis shows that what is true of the whole area is true also of a part of the area. The results of the experiments made by the "Garland" in St. Andrews Bay serve to show that even in this restricted region the plaice increase in numbers towards the north and the dabs towards the south. Four stations were examined in successive years and the results are given - the mean of six years - in the following table:

$\begin{array}{rcc} & \text { Plaice } & \text { Dab } \\ \text { North Station 4 } & 72 & 25 \\ \text { Station 3 } & 59 & 38 \\ \text { Station 2 } & 52 & 45 \\ \text { South Station 1 } & 51 & 46\end{array}$

It may be further said therefore that in the areas as specified above there is not merely a determination of plaice to the north and of dabs to the south but even in the bays within the area a similar distribution occurs. This is still more clearly shown in fig. 5. The same has been evident in Northumberland. Some years ago the trawl net was injured by an anchor at the north end of Druridge Bay, and since then the experiments have been kept more to the middle and southern part of the bay. Since the accident occurred the results have indicated the presence of relatively fewer plaice and more dabs. This is clear from the following table which

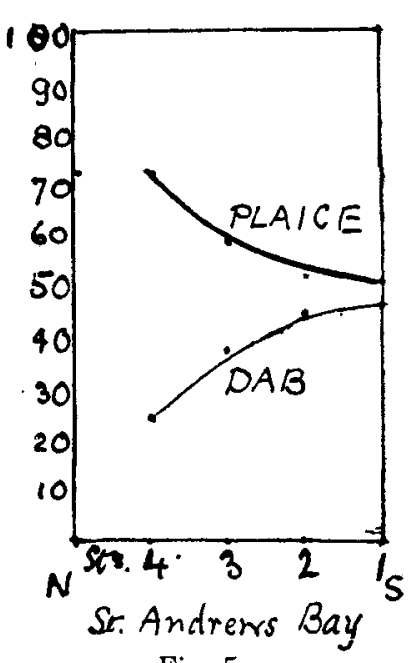

Fig. 5. gives the mean eatch per hour, (a) to 1905, and (b) from 1906 to 1908.

$\begin{array}{ccr} & \text { Plaice } & \text { Dab } \\ \text { (a) } & 40 & 64 \\ \text { (b) } & 34 & 100\end{array}$


A. Meek.

An experiment in Alnmouth Bay made this year with this in view indicated also a relatively larger number of plaice in the northern part of the bay.

The second part of the law is, therefore, that what is true of the area as a whole is likewise true of a subdivison of the area.

\section{The Factors which Determine the Distribution.}

The above will serve to roughly state the law. An attempt may. now be made to indicate the factor or factors which determine the distribution.

The topographical features of the Northumberland coastal region have already been referred to. It was supposed at first that the difference between the two divisions of Northumberland in this respect was sufficient to account for the contrasts exhibited in the distribution of fish. But it is at once evident that this feature has nothing to do with it. The north and the south end of the various bays cannot always be said to be so distinct with regard to the distribution of soft and hard ground. St. Andrews Bay shows an exactly opposite condition to that of Northumberland in this respect, and yet the distribution of the plaice and dabs is the same.

It is evident that if the structure of the ground over such wide areas as have been considered, and certainly in the smaller areas where the law is equally well exhibited, is not the cause, the only other factor which can be appealed to is migration. We have not sufficient evidence yet to clearly indicate for the important marine fish a distinct and definite migration to and from the spawning and feeding grounds, such as we have in cases where the migration is so pronounced as in the case of the eel, and of the marine Salmonidae. But such as we do possess for the plaice and the dab of the east coast of England and Scotland points to a migration of plaice northwards and of dabs southwards for spawning.

The following table exhibits the results of the marking experiments made in Northumberland, and those of the "Goldseeker" as given by Fulton ${ }^{1}$ ) with reference to plaice which migrated 20 miles and over:

$\begin{array}{lcc} & \text { North } & \text { South } \\ \text { Northumberland } & 9 & 1 \\ \text { Goldseeker } & 64 & 9\end{array}$

1) 1913. 5 th, Rep. (N. area) on Fishery and Hydrog. Investigations. 
The lesser movements of plaice which are usually immature are either north or south along the coast, and would require careful analysis to indicate for them alone any distinct bias in a given direction. It certainly appears from the results that the southerly movement along the Northumberland coast usually takes place in spring and summer, and the northerly migration in all seasons. In the case of the marking experiments of the "Goldseeker" about an equal number moved in a northerly and a southerly direction for 10-20 miles. But from 5-10 miles the movement was found to be in the majority of cases to the south. This is different however from the earlier experiments made by Fulton, when the movement (11th Rep. Scottish Fishery Board 1893) was found to be with few exceptions a northerly one. We thus know at all events that plaice may migrate in either direction, and that when they become mature they migrate as a whole northwards. From both the Northumberland and the Scottish experiments it may be seen, however, that in the northern part of a given area there is a a marked tendency to southerly migration, and in the southern part to northerly migration.

The Northumberland experiments with reference to the dab show without exception that the migration is southwards and eastwards, in the case of those leaving the coast where they were marked. In some instances also they have been found at a more southerly position along the coast. A return migration has not yet been demonstrated, and to be sure about it dabs would have to be marked off-shore.

The trawling experiments of Northumberland have shown that the plaice and dabs practicaliy altogether leave the coast about November returning about April. Merely a remnant of the summer profusion is left and a remnant which presents more plaice than dabs, the latter almost entirely leaving the coast during the winter. The same is more or less illustrated by similar experiments made elsewhere.

With all these considerations in mind together with the facts of distribution as set forth above, it is becoming plain that every year there is a migration of mature plaice to the north and east for spawning purposes, followed in a similar direction, but not so far, of immature plaice, and a return migration in the opposite direction to the feeding area, the immature arriving first. This latter movement leads to the annual appearance of plaice in the inshore waters where indeed they are joined later by mature plaice. 
Such a double movement off-shore to the north and east and inshore to the south and west would result with reference to a particular wintering ground of such a distribution as has been indicated.

This is perhaps even more decidedly demonstrated from what we know of the distribution and migration of dabs. They evidently leave the coast southwards and eastwards and return northwards and westwards, a neighbouring wintering ground being the locus of the outward movement and a related coastal region the place of wider distribution for feeding purposes. The return movement has been indicated in some of the "Garland" experiments. For instance in 1893 the dabs appeared first at the southern Aberdeen stations. In Northumberland also in 1909 - the only year the winter and spring conditions were investigated - dabs appeared first at the southern stations.

If this be the case such a general outward and inward movement would give rise to such a distribution as has been described.

It has been assumed from the facts which have been so far analysed that plaice and dabs alternate along the coast in preponderance. And if the above explanation be accepted as being with our present knowledge, the most likely one, it naturally results that the spawning grounds will also alternate. This is probably the case but it would not disturb the main point at issue, if a double maximum for either species were found, or even a region of sub-equal distribution.

At the risk of labouring the point it may be stated that the distribution of flounders is like that of plaice, and the mature flounders migrate to the north-(V. Northumberland Reports). Turbot may be said to be similarly distributed and they likewise migrate outwards in a northerly direction.

For these reasons it may be presumed that soles migrate for winter to the south of the Northumberland region; and the distribution of gurnards is such as to leave the impression that the spawning ground is to the north-east of Coquet Island.

It is probable also from a consideration of the catches of the fishermen that cod and the majority of the Gadoids spawn to the north of the Northumberland region. But it is not desired at present to press the case for round fish. In the case of Crustacea it may be found that the original view as to the influence of the ground is a chief if not the only factor. 
There is another view that might be forcibly argued. Seeing that the main current is from N. E. to S. W. the eggs and the larvae would be carried in the direction of the current and the fish would for that reason tend to be more numerous on that part of the coast where the larvae would mainly arrive. Such a contention would fairly satisfactorily account for the distribution of northerly migrants but not for southerly migrants.

If it is necessary to restate the law in the light of the explanation which has been attempted it might be put in the following terms.

There are a succession of wintering grounds off the east coast and these are correlated with feeding grounds along the. coast. Plaice, turbot, brill, and flounders have the wintering grounds to the north of the feeding grounds and dabs and soles to the south. As a consequence of the migration to and from the wintering grounds the northerly migrants (e. g. plaice), are more numerous on the north side of the area, and the subdivisions of the area, and the southerly migrants ( $\theta$. g. dabs) predominate on the south side of the area, and of its sub-divisions.

Or, in a word, - The species predominates on the feeding ground, and on the sub-divisions thereof nearest to the wintering ground.

These points are considered with fuller details in a further paper on the subject, which will be published in the forthcoming Report of the Dove Marine Laboratory. 